\title{
O espaço vivido e a percepção de problemas ambientais a partir do uso de mapas mentais em escola urbana de Rosário do Sul, RS
}

The city space and the perception of environmental problems from the use of mental maps in an urban school in Rosário do Sul, RS

\author{
Melina Dornelles Severo', Mauro Kumpfer Werlang² \\ 'Mestre em Geografia e Geociências, Universidade Federal de Santa Maria, Santa Maria, Brasil \\ ${ }^{2}$ Departamento de Geociências, Geografia Física. Universidade Federal de Santa Maria, Santa Maria, Brasil
}

\begin{abstract}
Resumo
Os problemas ambientais intensificaram-se com a sedentarização do homem, promovendo uma modificação da paisagem natural face ao surgimento das cidades. Muitas cidades brasileiras apresentam problemas motivados pela carência de planejamento, pela poluição do ar e da água, pelo esgotamento sanitário e pelos resíduos sólidos, por moradias irregulares e em áreas de risco, entre tantos outros problemas que afetam a qualidade de vida nas cidades. O presente trabalho teve como objetivo avaliar, a partir do uso de mapas mentais na escola, como jovens adolescentes alunos do oitavo ano da Escola Estadual de Ensino Médio Padre Ângelo Bartelle no município de Rosário do Sul, RS percebem os problemas ambientais urbanos em seu espaço vivido. Para alcançar esse objetivo utilizou-se o conceito de percepção ambiental a partir do uso de mapas mentais. Os mapas mentais foram confeccionados pelos alunos da Escola e, neles se buscou representar alguns problemas ambientais percebidos no espaço vivido desses alunos. Os problemas ambientais representados nos mapas mentais foram considerados aqueles mais percebidos dentro do espaço vivido. Os mapas mentais foram analisados a partir do método fenomenológico e da proposta de Kozel (2001). Muitos e distintos problemas ambientais foram destacados, entretanto, os mais frequentes estiveram relacionados com a poluição derivada dos resíduos sólidos. Pôde-se concluir que a percepção dos problemas ambientais do espaço vivido apresenta uma forte relação com o comportamento da sociedade frente ao consumo de produtos.
\end{abstract}

Palavras-chave: problemas ambientais; percepção; mapas mentais; educação ambiental.

\begin{abstract}
The environmental problems are stronger with the sedentarization of the man, promoting a changing in the natural landscape with the emergence of cities. Many brazilian cities have problems caused by lack of planning, pollution of air and water, water by sewage and solid waste, for irregular housing and risk areas, among many other problems that affect the life quality in cities. This study aims to evalueate, from the use of mental maps in the school, as young teenagenrs of the eigth year of the Escola Estadual de Ensino Médrio Padre Ângelo Bartelle, in the municipality of Rosário do sul, RS, perceive the urban environmental problems in the city space. To achieve this we used the concept of environmental perception from the use of mental maps. The mental maps were made by the students of the school, and in them is sought to represent some environmental problems perceived in the city space of this students. The environmental problems represented in the mental maps were those most commonly perceived in the city space. The mind maps were analysed from the phenomenological method and from the Kozel's propose (2001). Many and various environmental problems were highlighted, however, the most frequent were related with the pollution from solid waste. It was concluded that the perception of environmental problems in the city space has a strong relation with the society's behavior towards the consumption of products.
\end{abstract}

Keywords: environmental problems, perception, mental maps, environmental education. 


\section{INTRODUÇÃO}

Nas últimas décadas, a humanidade passou por uma série de mudanças de ordem tecnológica, o que acabou afetando as relações humanas e destas com o meio natural (SAMPAIO; LEITE, 1999). Conforme Loureiro (2003) o cenário atual no qual nos movemos atualmente, onde se "coisificam" tudo e todos, onde há uma enorme banalização da vida, e onde se exaltam movimentos de individualismo exacerbado das pessoas e de dicotomização na compreensão do humano como partes integrantes da natureza é, em tese, antagônico a projetos de cunho ambientalista.

A banalização, em todos os aspectos da vida, onde os padrões de consumismo exagerado da sociedade atual, não contribuem em nada para a preservação do meio ambiente e para as mudanças de pensamento e de postura da sociedade, o que é tão necessário nos dias de hoje em face de tantas mudanças, desordens e conflitos.

São diversos os problemas ambientais que situados no meio urbano, como por exemplo, poluição dos recursos hídricos, devastação da vegetação ciliar em áreas de proteção permanente, erosão do solo e assoreamento de cursos d'água, diversas formas de poluição (ar, sonora, visual), além de problemas relacionados aos resíduos sólidos, entre inúmeros outros problemas ambientais.

Questões relacionadas à conservação e a preservação do meio ambiente, articuladas com a Educação Ambiental (EA) vêm sendo, atualmente, muito trabalhadas nas várias esferas da sociedade. A atuação de profissionais de diversas áreas do conhecimento na EA visa primeira conscientizar a sociedade e, em seguida, melhorar o ambiente onde as pessoas encontram-se inseridas.

Uma mudança na percepção que a sociedade tem do meio ambiente, talvez, seja o maior obstáculo a ser superado pela EA, pois tanto o cidadão (no caso o aluno) como os cidadãos em geral convivem numa perspectiva equivocada de que os recursos naturais são renováveis, portanto infinitos. Essa concepção traz consigo a herança de uma cultura de que a natureza não é sua responsabilidade, mas sim dos entes governamentais, que estão, portanto isentos e descompromissados com o meio ambiente.

Os mapas foram, desde o início dos tempos o principal objeto e campo de estudo da geografia, pois, estes são representações da superfície terrestre e dos fenômenos que nela acontecem. Conforme Raisz (1969) a história dos mapas é tão antiga quanto à história da própria humanidade, visto que os mapas surgiram antes mesmo da invenção da escrita.

Foram utilizados para mapear lugares e fatos desde a antiguidade, pois os homens nesse período da história da humanidade eram nômades e "conheciam o mecanismo das estações, fazendo migrações, às vezes de longos percursos a fim de acompanharem os animais silvestres que utilizam como alimentos ou para colherem os frutos de determinada área" (ANDRADE, 1987, p.21). Salienta Raisz (1969, p. 07), "[...] fazer mapas é uma aptidão inata da humanidade", assim a representação do espaço é algo que faz parte do homem, desde o princípio dos tempos fazendo parte da sua sobrevivência na terra.

Os mapas mentais aparecem como uma representação da superfície, mas que está no campo da percepção, da imaginação de cada ser humano. Assim, os mapas mentais podem se constituir numa ferramenta para se trabalhar com EA. Niemeyer $(1994$, p.6) destaca que estes "[...] sempre transmitem a percepção que um determinado sujeito tem, em uma ocasião particular, sobre o meio ambiente". Nesse sentido, o professor pode trabalhar com a percepção do aluno em relação ao meio em que ele vive através dessas representações que habitam o seu imaginário, fazendo inferências sobre a realidade que é vivida por esse aluno, e assim ajudá-lo a transformá-la.

No ambiente escolar, muitas situações, identificam-se dificuldades para a EA ser trabalhada num contexto da prática de Educação Ambiental Crítica e Emancipatória. Isso acontece, muitas vezes, devido à dificuldade em relacionar os conteúdos com a realidade do ambiente vivido, visto que nas escolas subsistem diferentes contextos em várias perspectivas sociais, econômicas e ambientais. Essas dificuldades influem no sentido de que os problemas relacionados aos resíduos sólidos acabam por ter uma preferência de abordagem, que de acordo com Loureiro (2003) parte sempre de um pressuposto equivocado: o de que o lixo sempre é o principal problema no ambiente escolar, e assim acabam sempre reproduzindo dentro do âmbito escolar práticas de EA voltadas para a reciclagem, não trabalhando outros aspectos importantes do meio ambiente. Acredita-se, portanto, que ao trabalhar-se a partir da percepção do aluno em relação ao ambiente vivido, por meio dos mapas mentais, o professor consiga abordar outros temas além do dos resíduos sólidos, bem como inserir no contexto escolar, uma Educação Ambiental Crítica e Emancipatória, explorando outros problemas ambientais existentes no meio 
ambiente e no contexto do espaço vivido.

Acredita-se que os mapas mentais podem ser utilizados de maneira eficaz para trabalhar a EA no contexto da prática de Educação Ambiental Crítica e Emancipatória. Conforme Oliveira (2006)

cada cidade tem seu próprio estilo, cada bairro tem suas características próprias, cada vila tem sua identidade. Essa diferença deve-se a um conjunto de características ambientais, sociais, culturais, espaciais e locacionais. São essas características do lugar que levam os indivíduos a terem imagens diferentes uns dos outros. A formação mental de cada um deve-se às relações do meio onde estão inseridos e as relações consigo mesmo e a sua capacidade de abstrair do mundo real aquilo que é visível a si mesmo. (OLIVEIRA, 2006 b, p.45).

Portanto, podem-se considerar os mapas mentais como importantes ferramentas para resgatar o ambiente vivido e introduzir uma Educação Ambiental Crítica Emancipatória e transformadora para com o lugar onde esses jovens vivem fazendo com que entendam e sintam-se integrantes do meio ambiente, para que possam ajudar a transformar a realidade.

Nesse sentido, o trabalho teve como objetivo avaliar, a partir do uso de mapas mentais na escola, como jovens adolescentes alunos do oitavo ano da Escola Estadual de Ensino Médio Padre Ângelo Bartelle, no município de Rosário do Sul, RS percebem os problemas ambientais urbanos em seu espaço vivido. Para alcançar esse objetivo buscou-se: (1) refletir com os alunos da $7^{\mathrm{a}}$ série do Ensino Fundamental da Escola Estadual de Ensino Médio Padre Ângelo Bartelle, sobre o conceito de percepção e buscar estabelecer uma conexão com a problemática ambiental local e com ações de cidadania; (2) avaliar a capacidade discernimento desses alunos em relação aos problemas ambientais locais, utilizando-se de mapas mentais elaborados a partir da percepção do espaço vivido.

\section{METODOLOGIA}

Para a realização do trabalho, empregaram-se como procedimentos de investigação e análise os mapas mentais. Como sujeitos da pesquisa tiveram-se os alunos da $7^{\mathrm{a}}$ série da Escola Estadual de Ensino Médio Padre Ângelo Bartelle que está localizada na área urbana do município de Rosário do Sul, RS, no bairro Centro cidade. Os alunos envolvidos na pesquisa têm idade entre 13 e 15 anos. Trabalhou-se com 80 alunos durante os meses de março e abril de ano de 2012, durante as aulas da disciplina de geografia.

Optou-se pela $7^{\mathrm{a}}$ série do Ensino Fundamental por esta estar inserida no $4^{\mathrm{o}}$ ciclo de estudos dos PCNs para o Ensino Fundamental. Neste ciclo, os alunos devem ser responsáveis entre outros objetivos por: (1) compreender a cidadania como forma de participação social e política, bem como exercício de direitos e deveres políticos, civil e social, como forma de adotar, no dia-a-dia, atitudes de solidariedade, cooperação, respeitando o outro e exigindo para si o mesmo respeito; (2) posicionar-se de maneira crítica, responsável e construtiva nas diferentes situações sociais, utilizando o diálogo como forma de mediar conflitos e de tomar decisões coletivas; (3) perceber-se integrante, dependente e agente transformador do ambiente, identificando seus elementos e as interações entre eles, contribuindo ativamente para a melhoria do meio ambiente; (4) questionar a realidade formulando-se problemas e tratando de resolvê-los, utilizando para isso o pensamento lógico, a criatividade, a intuição, a capacidade de análise crítica, selecionando procedimentos e verificando sua adequação (BRASIL, 1998).

Ao se considerar que o estudo sobre Educação Ambiental Crítica visa a inter-relação entre todos os elementos, tanto os elementos naturais quanto os elementos humanos, todos relacionados como um sistema procurou-se abordar e trabalhar com os alunos, a relação da sociedade com a natureza, observando essa relação pautada na ótica do consumo. De forma, buscou-se conscientizar os alunos de que somos responsáveis pelo ambiente onde vivemos.

Tomou-se o método fenomenológico como aporte teórico metodológico para o trabalho. Este método tem como base a percepção e o espaço vivido. Segundo Pereira et al (2010, p.174) "a geografia fenomenológica está pautada na percepção, considerando o mundo vivido e a subjetividade, que é suma importância para a compreensão do espaço". Portanto a escolha deu-se no sentido de que a temática envolve o espaço vivido e as relações afetivas que os alunos da Escola Estadual de Ensino Fundamental e Médio Padre Ângelo Bartelle têm com o espaço onde vivem. Assim, o método parte 
como forma de identificar os principais problemas ambientais urbanos a partir da aplicação de mapas mentais. A partir dos mapas que os alunos confeccionaram, identificam-se, a partir do espaço vivido por eles, os principais problemas ambientais dentro do espaço urbano, visando assim, introduzir uma prática de EA para com o lugar onde esses alunos vivem.

Os procedimentos operacionais do trabalho constituíram-se de quatro etapas. Na primeira etapa buscou-se refletir, junto aos alunos da $7^{\mathrm{a}}$ série do Ensino Fundamental da Escola Estadual de Ensino Médio Padre Ângelo Bartelle acerca do conceito de percepção, buscando estabelecer conexões entre a percepção e os problemas ambientais percebidos no espaço vivido. Nesse sentido, trabalhou-se, por exemplo, o que se entende por percepção e como percebemos o ambiente onde vivemos. Para isso foi oportunizado um resgate sobre o significado da palavra percepção a fim de introduzir o tema e, posteriormente identificar o espaço vivido e os problemas presentes nele. Numa segunda etapa buscou-se estabelecer uma relação do consumo com o problema ambiental, relacionando-os com o espaço vivido, local e globalmente. Na terceira etapa, buscou-se identificar a percepção a partir da elaboração, no decorrer das aulas, dos mapas mentais. Para isso, foram colocadas motivações sobre o espaço vivido, de acordo com o que cada aluno percebia na sua realidade dentro do espaço vivido por ele. A figura 1 ilustra a etapa relativa à elaboração dos mapas mentais pelos alunos da turma 712 da Escola Estadual de Ensino Médio Padre Ângelo Bartelle.

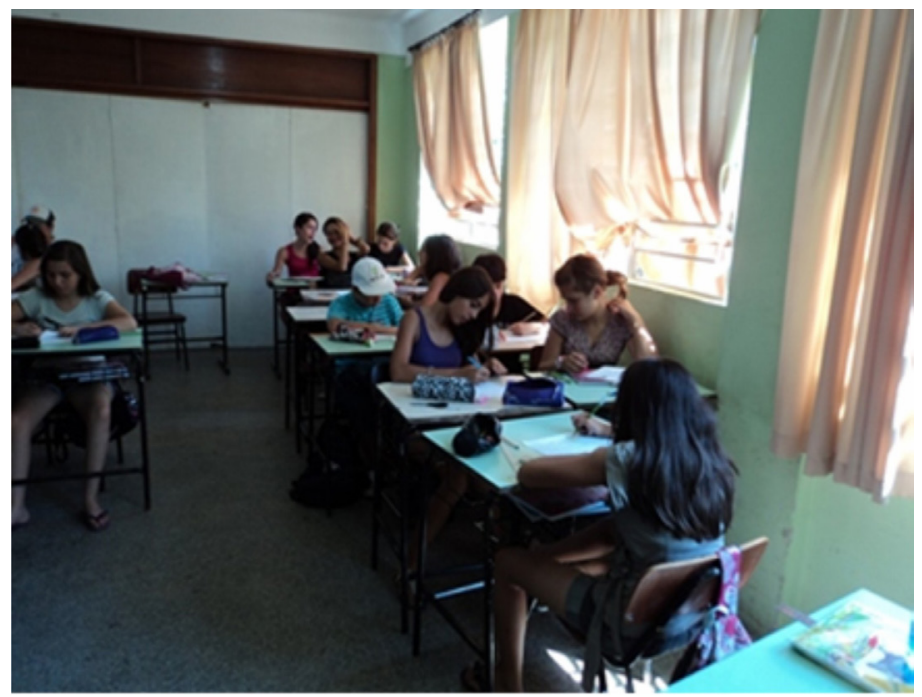

Figura 1: Elaboração dos mapas mentais pelos alunos da turma 712 da Escola Estadual de Ensino Médio Bartelle, no município de Rosário do Sul, RS.

Padre Ângelo

Seguindo na terceira etapa, esse momento da atividade de elaboração dos mapas mentais, foi muito importante uma vez que permitiu aos alunos expressar, através dos mapas mentais, como cada um percebe a realidade de seu espaço vivido. Oliveira (2006) observa que esses mapas são importantes ferramentas para o professor poder entender a realidade do aluno e destaca que

[...] cabe a cada cidadão dar sua parcela de colaboração, pois são as pequenas ações que resultam em grandes mudanças. Desta forma, acredita-se estar na educação o meio mais eficaz para amenizar a atual problemática ambiental. Assim, cabe aos educadores, enquanto colaboradores na formação de indivíduos, desenvolverem projetos que levem os educandos a compreenderem o seu meio vivido e o que fazer para amenizar os problemas que ali ocorrem (Oliveira, 2006, p.33).

Portanto, pequenas ações são responsáveis pelas grandes mudanças que podem ser obtidas no ambiente. Acredita-se que trabalhando com os problemas ambientais percebidos a partir de mapas mentais, pode-se inserir uma EA voltada para os problemas ambientais do espaço vivido na comunidade, permitindo melhores resultados.

Para a confecção dos mapas mentais, os alunos se utilizaram de folha de papel branco tamanho A4, lápis de escrever, lápis de cor para colorir (para quem preferisse, pois, não foi exigido que o desenho fosse colorido), régua e borracha. Os mapas foram elaborados pelos alunos durante as aulas 
de geografia, sem nomes que os identificassem. Foram utilizadas duas horas aulas para a atividade de confecção dos mapas mentais pelos alunos. A atividade foi desenvolvida partir do dia 05 de março de 2012 e teve sua conclusão no dia 16 de abril de 2012, envolvendo atividades durante sete semanas. Como a disciplina de geografia, na escola, conta com uma carga horária semanal de duas horas, a atividade totalizou quatorze horas.

A quarta etapa consistiu na avaliação dos mapas mentais, elaborados pelos alunos, a partir do método de análise proposto por Kozel (2001). Essa metodologia tem como parâmetros para análise dos mapas mentais, a interpretação destes quanto à forma de representação dos elementos que estão contidos na imagem por intermédio dos ícones que são representados por quem os elabora. Oliveira (2006) destaca que estes ícones representados podem ser: representação da imagem natural, representação da paisagem natural; representação da paisagem construída e representação da paisagem vivida pelos alunos e os objetos móveis que são representados por eles. De acordo com Kozel (2009, p.01): "[...] a representação é aqui considerada como uma forma de linguagem impregnada de significados e valores sociais refletindo a realidade ou vivência social dos indivíduos". Nesse sentido, torna-se necessário analisar cada um desses códigos contidos nas imagens representadas pelos alunos.

\section{RESULTADOS E DISCUSSÃO}

$\mathrm{Na}$ análise dos resultados, fez-se uso do método fenomenológico. Para interpretar e analisar os mapas mentais adotou-se o método proposto por Kozel (2001), que considera os elementos contidos na imagem, foram analisados os mapas mentais elaborados pelos alunos. Oliveira (2006) também faz uso deste método de análise ao desenvolver a dissertação "Percepção dos resíduos sólidos (lixo) de origem domiciliar, no bairro Cajuru: Curitiba-PR: um olhar reflexivo a partir da Educação ambiental". Portanto, constituíram os resultados a serem discutidos, os mapas mentais produzidos pelos alunos da $7^{\mathrm{a}}$ série do Ensino Fundamental da Escola Estadual de Ensino Fundamental e Médio Padre Ângelo, a partir da percepção registrada por eles, em relação aos problemas ambientais urbanos no espaço onde vivem, seja no seu bairro, na sua rua ou em lugares próximos a escola.

Foram confeccionados 81 mapas mentais. Frente a isso, foram agrupados 16, representando os níveis de análise propostos por Kozel (2001). Esse agrupamento buscou as expressões das representações dos problemas ambientais mais freqüentes observadas no universo dos mapas realizados pelos alunos.

Os resultados permitiram observar que os alunos apresentam diferentes percepções do espaço vivido. Embora, o espaço vivido seja o mesmo, ou até mesmo a mesma rua, a percepção registrada nos mapas mentais difere. Isso demonstra que ela é única e proporciona uma visão de mundo de forma individualizada. Constatou-se também, que alguns problemas percebidos são freqüentes dentro do espaço vivido, e assim, há uma freqüente repetição na representação desses problemas nos mapa mentais, principalmente daqueles que dividem o mesmo espaço vivido.

A maioria dos mapas mentais foram representações de imagem na forma horizontal (Kozel, 2001). Isso pode estar relacionado a uma maior facilidade nesse tipo de representação, ou ainda, devido à razão desses alunos apresentarem problemas relacionados à noção de espacialidade.

Nas representações em formas horizontais e, nas representações em formas de quadras e quadros, observaram-se alguns elementos descritos na metodologia proposta por Kozel (2001) como elementos da paisagem natural, elementos da paisagem construída, elementos móveis e representação de elementos humanos.

Os elementos da paisagem natural que mais apareceram nos mapas mentais foram árvores, arbustos, jardins com flores e gramados e animais como cães e aves. Dentre as representações de elementos naturais, quase sempre havia algum problema ambiental associado e na maioria das vezes eram resíduos sólidos jogados na rua ou sujeira causada por animais e pessoas. Apareceram também alguns mapas com ausência de representação de indicação de problemas ambientais, contendo apenas elementos naturais. Isso permite a constatação de que alguns alunos negam, desconhecem ou não percebem os problemas do seu meio vivido ou o preferem representar como belo, limpo e sem problemas.

Os elementos da paisagem construída foram por prédios, casas e ruas que se misturavam aos elementos da paisagem natural. Nesses casos a paisagem natural está representada de forma bastante impactada pela ação antrópica. Nos mapas mentais onde se encontraram elementos da paisagem construída, apareceram também elementos móveis. Em alguns mapas apareceram representados problemas 
relacionados com o barulho proveniente dos automóveis, a poluição visual, os buracos e a sujeira da via.

A figura 2 ilustra alguns elementos da paisagem natural e a figura 3 traz algumas representações da paisagem construída.

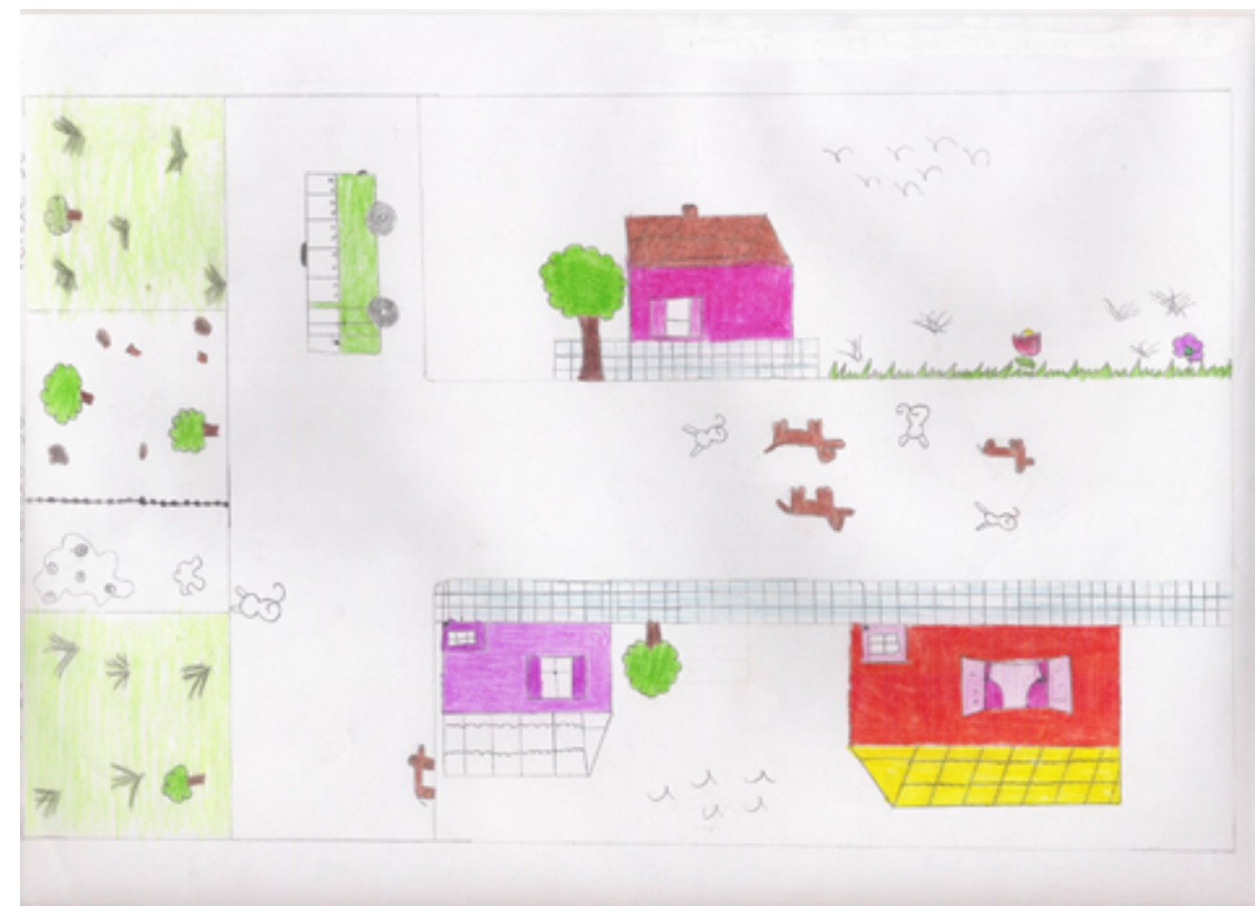

Figura 2: Mapa Mental elaborado por aluno da Escola Estadual de Ensino Médio Padre Ângelo Bartelle, no município de Rosário do Sul, RS onde aparece a presença de alguns elementos da paisagem natural.

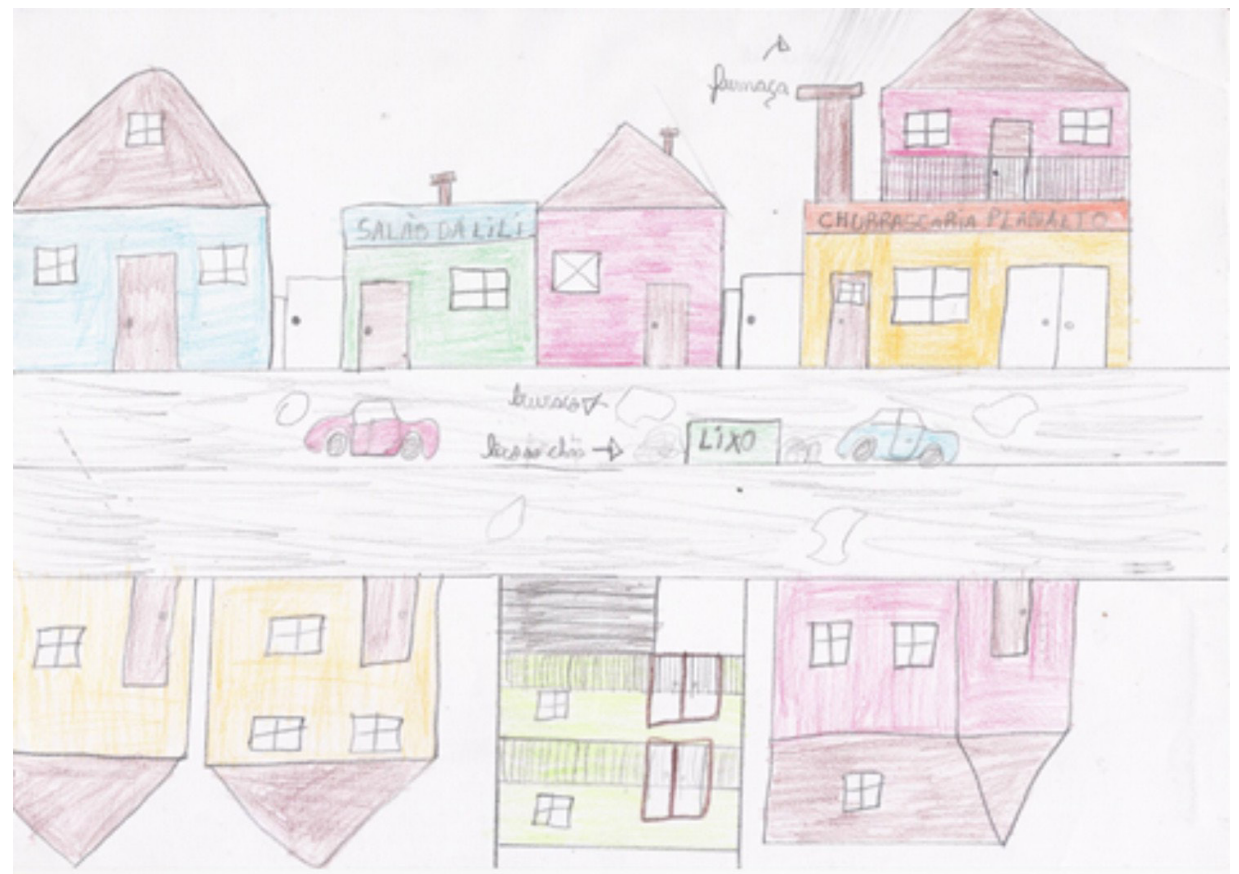

Figura 3: Mapa Mental elaborado por aluno da Escola Estadual de Ensino Médio Padre Ângelo Bartelle, no município de Rosário do Sul, RS onde predomina a presença de elementos da paisagem construída.

Nos mapas onde aparece a representação de humanos estão cenas de violência. Estas se referem à violência relacionada a assaltos e outras formas de criminalidade. Também nessas representações, aparece o registro de problemas relacionados aos resíduos sólidos e a animais abandonados e poluição 
sonora. A figura 4 mostra uma dessas representações.

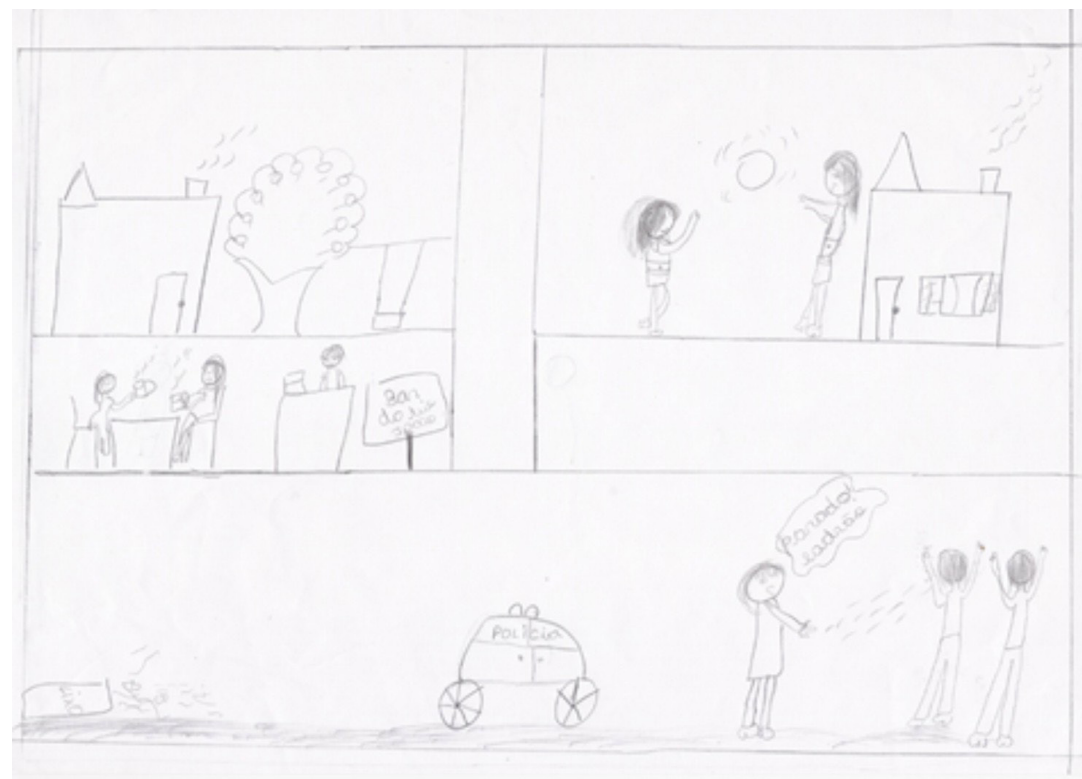

Figura 4: Mapa Mental elaborado por aluno da Escola Estadual de Ensino Médio Padre Ângelo Bartelle, no município de Rosário do Sul, RS onde aparece representação de humanos e cena de violência.

Houve também, situações em que os mapas mentais apresentaram ausência de problemas ambientais. Essa situação remete para a inferência de que esses alunos negam, desconhecem ou não percebem os problemas do seu meio vivido ou preferem o representar como belo, limpo e sem problemas. A figura 5 mostra uma situação onde o aluno representa seu espaço vivido sem a indicação de problemas ambientais. Já a figura 6 mostra a distribuição da freqüência dos problemas ambientais representados nos mapas mentais do espaço vivido dos alunos da Escola Estadual de Ensino Médio Padre Ângelo Bartelle, no município de Rosário do Sul, RS.

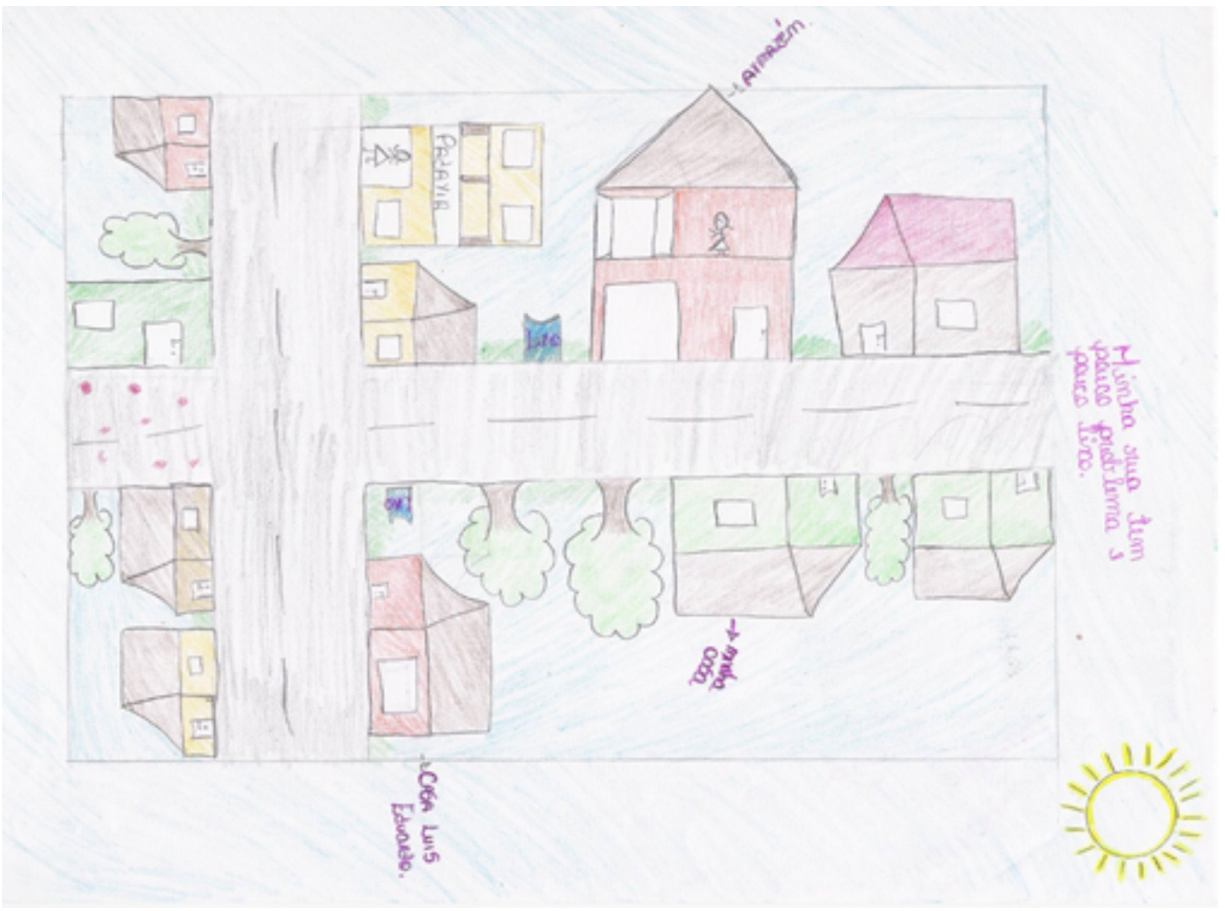

Figura 5: Mapa Mental elaborado por aluno da Escola Estadual de Ensino Médio Padre Ângelo Bartelle, no município de Rosário do Sul, RS onde o aluno representa seu espaço vivido sem a indicação de problemas ambientais. 


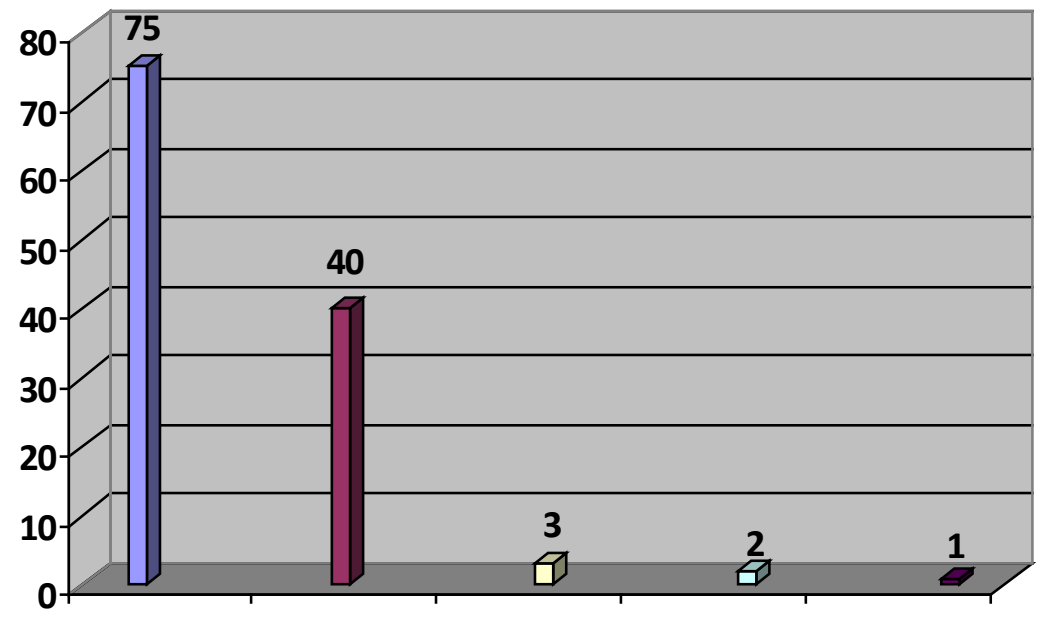

\begin{tabular}{|l|}
$\square$ Lixo \\
$\square$ Buracos na via pública \\
$\square$ Violência \\
$\square$ Poluição sonora \\
$\square$ Animais abandonados
\end{tabular}

Figura 6: distribuição da freqüência dos problemas ambientais representados nos mapas mentais do espaço vivido dos alunos da Escola Estadual de Ensino Médio Padre Ângelo Bartelle, no município de Rosário do Sul, RS.

A partir da análise das representações criadas pelos alunos que participaram das atividades, conclui-se que os problemas ambientais representados estão relacionados àqueles mais evidentes do seu espaço vivido. Neles os problemas ambientais mais percebidos foram primeiro os relacionados aos resíduos sólidos, aparecendo com muita freqüência. A figura 6 mostra a distribuição da freqüência dos problemas ambientais representados nos mapas mentais do espaço vivido dos alunos da Escola Estadual de Ensino Médio Padre Ângelo Bartelle, no município de Rosário do Sul, RS.

Em seguida estão os problemas relacionados à conservação das vias públicas. Muitos outros problemas ambientais aparecem nos mapas mentais, porém com menor freqüência como os relacionados com a violência, o barulho animais abandonados nas ruas.

\section{CONCLUSÃO}

A partir do trabalho foi possível avaliar como os alunos percebem os problemas ambientais urbanos dentro do seu espaço vivido. Espaço este, que é o lugar onde se relacionam, onde criam e estabelecem laços de afetividade e estão inseridos cotidianamente. Nesse sentido, foi possível refletir sobre o conceito de percepção bem como buscar estabelecer a conexão com a problemática ambiental do espaço vivido. Nesse sentido, a relação com o consumo e a associação com os problemas ambientais mostrou-se evidente quando os mapas mentais representam problemas relacionados aos resíduos sólidos. Assim, a avaliação da relação entre sociedade x consumo, na ótica da Educação Ambiental Crítica Emancipatória, permeia ações que podem ser propostas para melhorar o ambiente vivido. Os alunos têm desenvolvida uma percepção ambiental crítica do seu espaço vivido. Isso pôde ser avaliado por meio dos mapas mentais produzidos e analisado a partir da metodologia proposta por Kozel (2001).

\section{REFERÊNCIAS}

ANDRADE, M. C. de. Geografia Ciência da Sociedade. São Paulo: Atlas, 1987.

BRASIL-PARÂMETROS CURRICULARES NACIONAIS - Ensino Fundamental- $3^{\circ}$ Ciclo. Brasília: Secretaria de Educação Fundamental, MBC/SEF, 1998. 
BRASIL-PARÂMETROS CURRICULARES NACIONAIS - Ensino Fundamental- $3^{\circ}$ e $4^{\circ}$ ciclo. Brasília: Secretaria de Educação Fundamental. Brasília, MBC/SEF, 1998.

KOZEL, S. As linguagens como representações do espaço: uma proposta metodológica possível. In: XII ENCUENTRO DE GEOGRAFOS DE AMERICA LATINA, XII EGAL, 2009, Montevideo. Anais Eletrônicos. Montevideo: Universidad de La Republica, 2009. Disponível em:< http://egal2009.easyplanners.info/ area02/2088_KOZEL_Salete.pdf> Acesso em: 20 dez. 2011.

LOUREIRO, C. F. B. Premissas teóricas para uma educação ambiental transformadora. In: Revista eletrônica Ambiente e Educação, Rio Grande, v.8, 2003, p.37-54.

NIEMEYER, A. M. de. Desenhos mapas e orientação espacial: pesquisa e ensino de antropologia. Textos Didáticos. Campinas, IFCH. Unicamp,1994.

OLIVEIRA, N. A. Percepção dos resíduos sólidos (lixo) de origem domiciliar, no bairro Cajuru: Curitiba-PR: um olhar reflexivo a partir da Educação ambiental. 2006. 173f. Dissertação (Programa Pós-Graduação em Geografia); Universidade Federal do Paraná: Universidade Federal do Paraná, 2006.

PEREIRA, L. A. G, CORREIA, I.S. OLIVEIRA, A.P. Geografia fenomenológica: espaço e percepção. In: Revista eletrônica Caminhos da Geografia. Uberlândia, v.11. n.35. set. 2010. p.173-178.

RAISZ, E. J. Cartografia geral. 2 ed. Rio de Janeiro: Científica, 1969.

SAMPAIO, M. N.; LEITE, L. S. Alfabetização tecnológica do professor. 2 ed. Petrópolis: Vozes, 1999. 